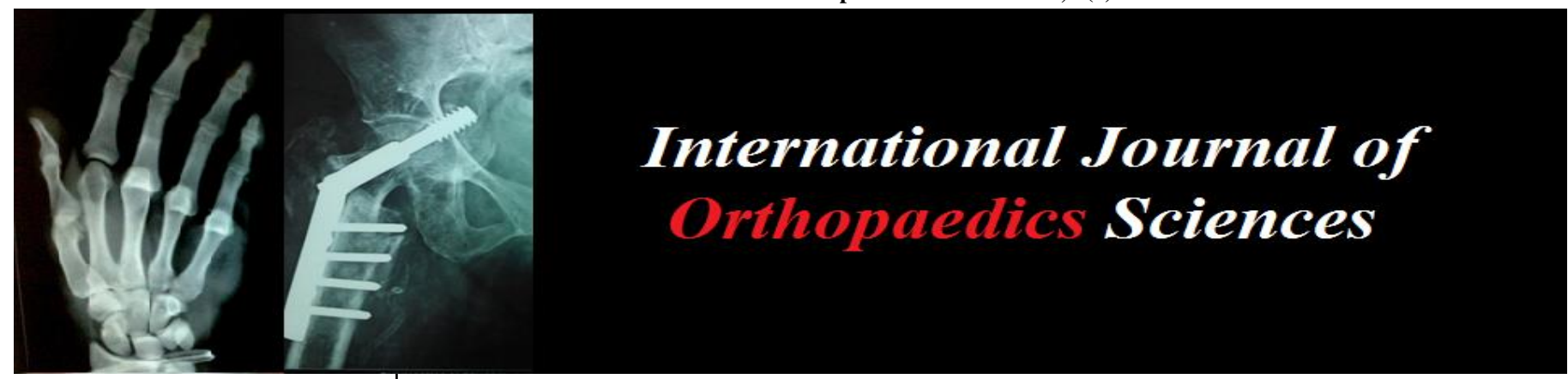

E-ISSN: 2395-1958

P-ISSN: 2706-6630

IJOS 2020; 6(4): 372-379

(C) $2020 \mathrm{IJOS}$

www.orthopaper.com

Received: 22-06-2020

Accepted: 05-08-2020

Senthilnathan Arumugam

Professor of Orthopaedics, Rajah

Muthiah Medical College and

Hospital, Annamalai University,

Tamil Nadu, India

Purushothaman Navaneethan M.S Ortho-Postgraduate Student, Department of Orthopaedics, Rajah Muthiah Medical College and Hospital, Annamalai University, Tamil Nadu, India

Prabhakar Ramabadran Lecturer, Department of Orthopaedics, Rajah Muthiah Medical College and Hospital, Annamalai University, Tamil Nadu, India

Vijayashankar Kaliyaperumal Assistant Professor, Department of Orthopaedics, Rajah Muthiah Medical College and Hospital, Annamalai University, Tamil Nadu, India

Corresponding Author: Purushothaman Navaneethan M.S Ortho-Postgraduate Student, Department of Orthopaedics, Rajah Muthiah Medical College and Hospital, Annamalai University, Tamil Nadu, India

\section{Comparative study on the complications of antebrachium fractures treated with flexible nailing in paediatric and adolescent age group}

\section{Senthilnathan Arumugam, Purushothaman Navaneethan, Prabhakar Ramabadran and Vijayashankar Kaliyaperumal}

DOI: $\underline{\text { https://doi.org/10.22271/ortho.2020.v6.i4f.2360 }}$

\begin{abstract}
Background: Antebrachium fractures in paediatric age group, which are unstable are more commonly treated nowadays using intramedullary titanium elastic nailing. Recent studies have showed a higher complication rates in adolescent population when compared to the paediatric counterpart. The aim and objective of this study is to compare the complication rates and outcome in paediatric and adolescent population treated using flexible nail.

Methods: An ethical committee approved study was conducted in Rajah Muthiah Medical College, Chidambaram from May 2018 to September 2020 on both bone forearm fractures in paediatric and adolescent population. In our study 20 cases of both bone forearm fractures, of which 10 belonging to paediatric age group (age less than 10 years) and 10 cases belonging to adolescent age group (age more than 10 years) treated with flexible intramedullary nail (TENS). These cases were followed up for period of 1 year and complications were quantified on the basis of Clavien - Dindo classification. Outcomes were analysed based on Martus et al. grading system.

Results: Out of 20 forearm fractures treated with tens nail in each age group, mean age was found to be 13.6 years in adolescent group and 9.2 years in paediatric group. Mean follow up period were42 weeks in adolescent category and 40 weeks in paediatric category. Average time and duration from the point of injury to the surgical procedure was 2 to 3 days in both groups. Closed reduction and internal fixation with tens nailing was done in 13 cases ( 8 paediatric and 5 adolescent group) and open reduction was needed in the remaining 7 cases ( 2 paediatric and 5 adolescent). The overall result of our study showed that complications were slightly higher in adolescent age group, when compared to the paediatric counterparts. P value between the two groups was not significant.

Conclusion: Tens nailing is an excellent technique for paediatric and adolescent fractures of forearm with very good functional outcome. Even though complications were seen in adolescent age group, it was significantly lower than those associated with other surgical techniques. However, with lesser complication rate in paediatric age group, we conclude that in fractures requiring surgical fixation, TENS nailing is more advantageous than other surgical options.
\end{abstract}

Keywords: antebrachium fractures, TENS, adolescent, paediatric, complications

\section{Introduction}

In paediatric population, forearm fractures are one of the commonest injuries. The main goal in the treatment of these fractures is to attain an acceptable alignment which gives a good functional ROM with minimal complications. The greater number of these injuries are treated by closed reduction, followed by the application of the plaster cast. Nevertheless, when the reduction is not adequate and when there is increased deformity in angular or rotational component, which leads to the loss of movements of the forearm. In various studies, the forearm movements essential for the activities of daily living (ADL) as been mentioned ${ }^{[1,2]}$. All these similar studies advocated that a $5^{0}$ to $30^{\circ}$ loss in pronation and $8^{0}$ to $35^{\circ}$ loss in supination will affect the ADL.

In our study, the inclusion criteria for operative treatment of these fractures were compound fractures and fractures which are not able to reduce by closed reduction methods. Based on the current guidelines, we adhere to the existing criteria for the alignment of these fractures ${ }^{[3]}$. 
Previous studies have already shown about the excellent efficacy of intramedullary nailing in forearm fractures ${ }^{[4-7]}$. There is no well-defined age limit upto when IM nailing can be done, but in our study, we selected patients based on physeal closure. There are many advantages of intramedullary nailing over conventional plating methods. Intramedullary nailing with TENS has the advantages of smaller incision, less operative time, shorter stay in hospital and implant removal is much easier. Nevertheless, in other studies it has been noted that patients with closed fractures treated with TENS nailing also have complications like compartment syndrome of about $10 \%{ }^{[8]}$. In our study, patients with both bone forearm fractures treated with TENS nailing were taken and complications were noted in the followup. These complications were graded based on the modified ClavienDindo classification ${ }^{[9,10]}$ and a new grading system by Martus et al. ${ }^{[11]}$ Further we compared the complications between the two groups based on age (less than 10 years and more than 10 years) and assessed which age group has more complication rates.

\section{Methods}

Paediatric cases of age 5 to 20 years with both bone forearm fractures, admitted in RMMCH from June 2018 till September 2020 were taken in our study. 20 paediatric patients with both bone forearm fractures fulfilling the inclusion criteria were treated with intramedullary TENS nailing. Fracture is considered unsatisfactory alignment when there is cortical contact of less than 50 percent and angulation of more than $10^{\circ}$ in both coronal and sagittal component. Post operatively all patients were immobilised in a slab for 4 to 6 weeks. Iv antibiotics were given for three days followed by oral antibiotics for subsequent 2 days. 13 cases ( 8 paediatric and 5 adolescent group) were treated by closed reduction with TENS under c-arm guidance.7 cases (2 paediatric and 5 adolescent) where closed reduction cannot be achieved open reduction was done by giving a mini incision over the fracture site. These cases were followed up for a period of 1 year.

Documentation of elbow and forearm movements of flexion, extension, supination, pronation were done at the terminal follow-up. Pain with daily activities, functional disability and postoperative complications were also noted. Refracture, if any in the operated cases was considered as a complication, when it was associated with delayed union. Schmittenbecher et al. ${ }^{[12]}$ defined delayed union as, when there is incomplete consolidation of the fracture even at 90 days. Incomplete union even after 6 months was taken as non-union.

Complications were graded using a modified Clavien - Dindo classification ${ }^{[9,10]}$. Complications which are just a deviation from the usual postoperative course and does not require an intervention are considered as grade 1. Complications which resolved with close monitoring, drug therapy and does not require any inpatient treatment are considered as grade 2. Inpatient management and reoperation which was not planned are considered as grade 3 complications. Limb or life threatening complications and treatment which resulted in an indefinite functional deficit were taken as grade 4 complications. Mortality was taken as grade 5 (Table 1).

Table 1: Modified Clavien-Dindo classification

\begin{tabular}{|c|c|c|}
\hline Complication grade & Definition & Asymptomatic delayed union Prominent implant \\
\hline 1 & $\begin{array}{c}\text { Deviation from a routine postoperative course without } \\
\text { the need for intervention }\end{array}$ & Superficial infection Transient nerve palsy \\
\hline 2 & $\begin{array}{c}\text { Resolution after outpatient management, pharmacologic } \\
\text { therapy, or close observation }\end{array}$ & Deep infection Implant migration requiring early removal \\
\hline 3 & Requiring inpatient management or reoperation \\
\hline 4 & $\begin{array}{c}\text { Complication that is limb threatening, life threatening, or } \\
\text { resulting in a permanent deficit }\end{array}$ & $\begin{array}{c}\text { Compartment syndrome Permanent nerve palsy Radioulnar } \\
\text { synondon rupture }\end{array}$ \\
\hline 5 & Death of patient & Postoperative mortality secondary to anaesthetic reaction \\
\hline
\end{tabular}

The outcomes were graded by a new grading system created by Martus et al. which takes into account both the postoperative complications graded by the modified ClavienDindo system ${ }^{[5,13]}$ and also the range of movements in the final follow up. $70^{\circ}$ pronation and $85^{\circ}$ supination was considered as a normal range ${ }^{[14-15]}$. Outcomes were said to be excellent if there was full ROM and complications less than or equal to grade 1 as occurred. If there was less than $10^{\circ}$ loss of movements and complications which were not more than grade 2 were considered to have good outcome. Fair outcome was said when there is a significant loss in ROM of about $10^{\circ}$ to $30^{\circ}$ with a complication of about grade 3 or less. Results with complications of about grade 4 or 5 and loss of ROM of more than $30^{\circ}$ were considered to be poor outcomes. (Table 2)

Table 2: Martus et al. grading system

\begin{tabular}{|c|c|c|}
\hline Outcome Grade & Range of Motion & Complication \\
\hline Excellent & Full & Grade 1 or none \\
\hline Good & $\begin{array}{c}\text { Loss of <10 degrees } \\
\text { pronation and/or supination }\end{array}$ & Grade 2 or less \\
\hline Fair & $\begin{array}{c}\text { Loss of 10-30 degrees } \\
\text { pronation and/or supination }\end{array}$ & Grade 3 or less \\
\hline Poor & $\begin{array}{c}\text { Loss of }>30 \text { degrees } \\
\text { pronation and/or supination }\end{array}$ & Up to grade 5 \\
\hline
\end{tabular}

Patients were grouped into two categories based on the age group, below 10 years of age as group 1 and more than 10 years of age as group 2. By statistical analysis two groups were compared and the risk factors for the particular complications were evaluated. Continuous variables were compared using Wilcoxon rank-sum test. Categorial variables were compared by using pearson $\mathrm{x}^{2}$ test. Statistical significance was said when there was P-value of less than 0.05 . 
- 15 years / male

- h/o fall
PRE OP XRAY

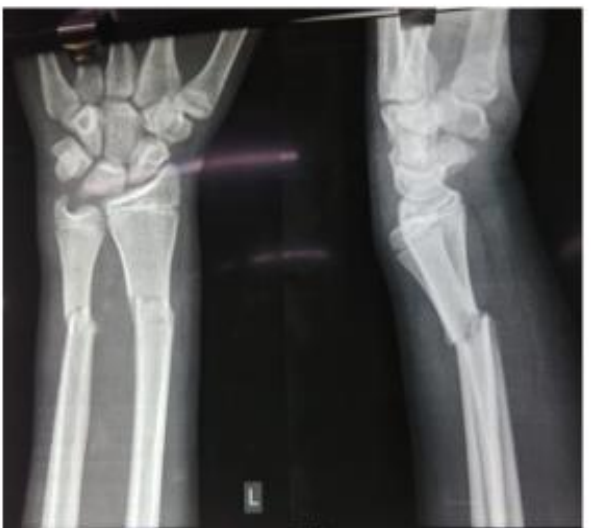

Immediate Post Op

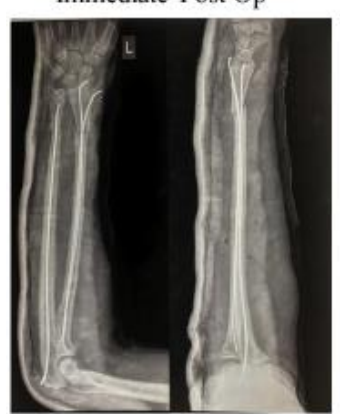

1 Month Old

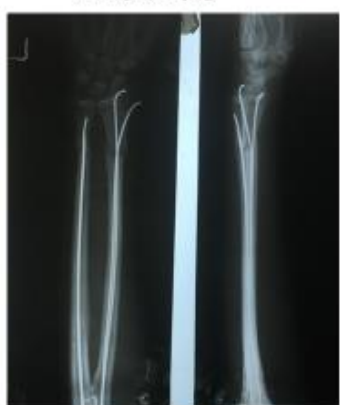

4 Months Old

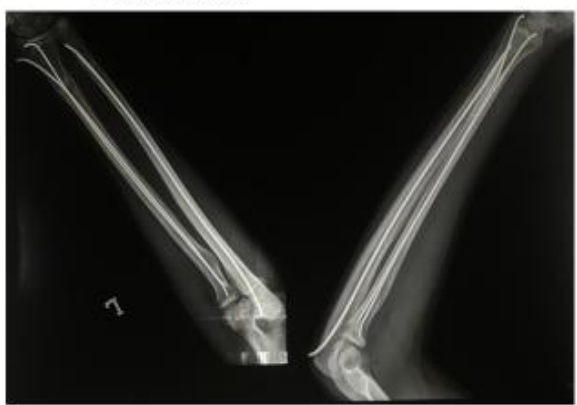

Implant Exit

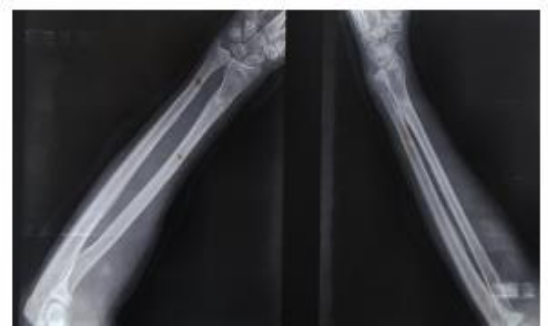

FLEXION

EXTENSION

PRONATION

SUPINATION

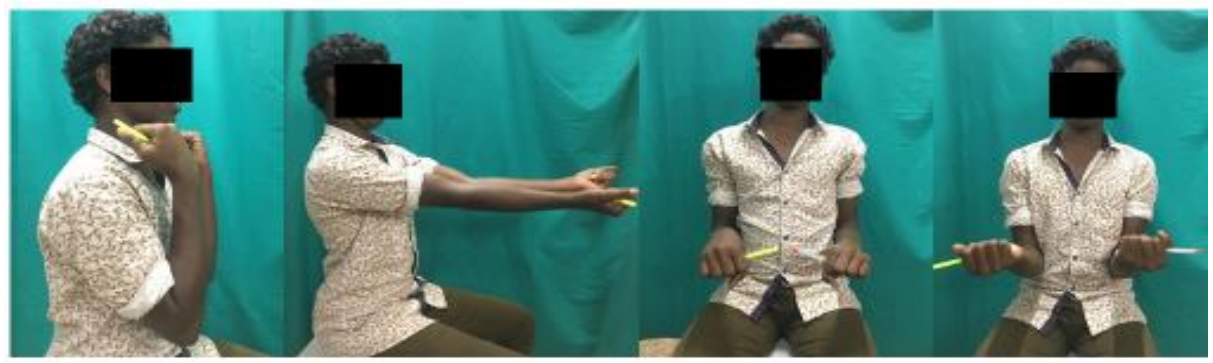

Case 1: (Adolescent group)
- 6 years/ fch
- $h / o$ fall
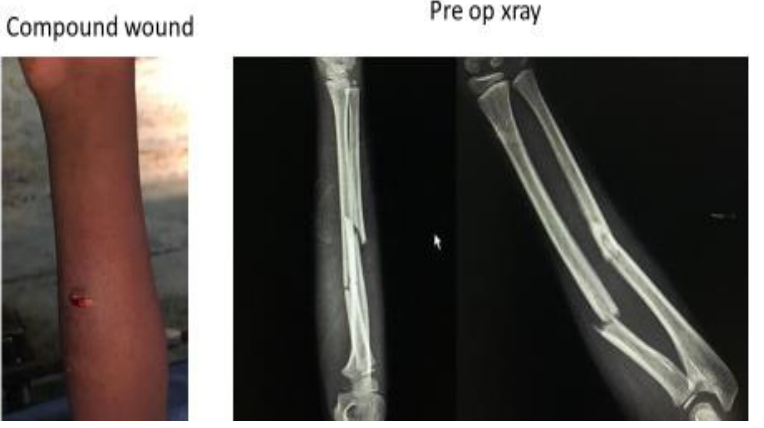
Immediate post op xray

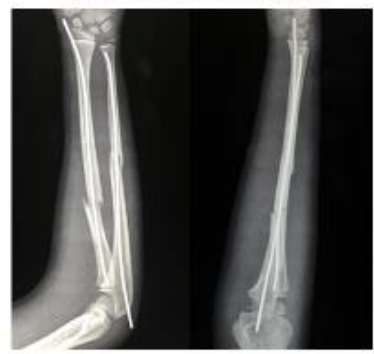

$6^{\text {th }}$ month xray

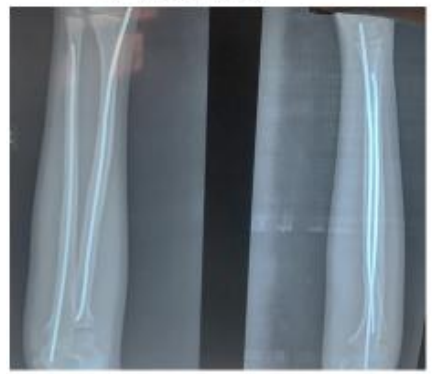

$1^{\text {st }}$ month xray

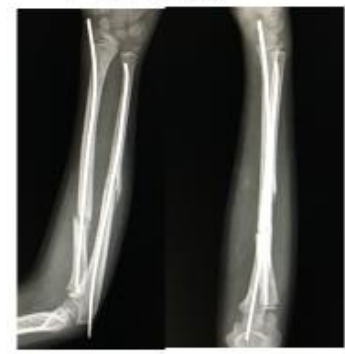

$3^{\text {rd }}$ month xray

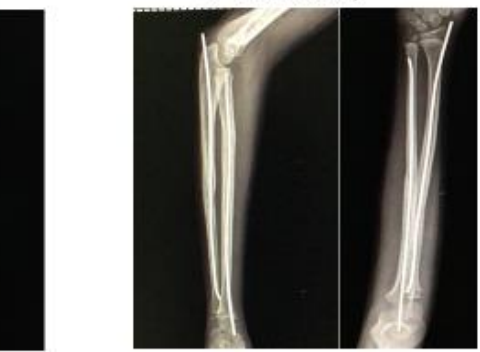

Implant exit

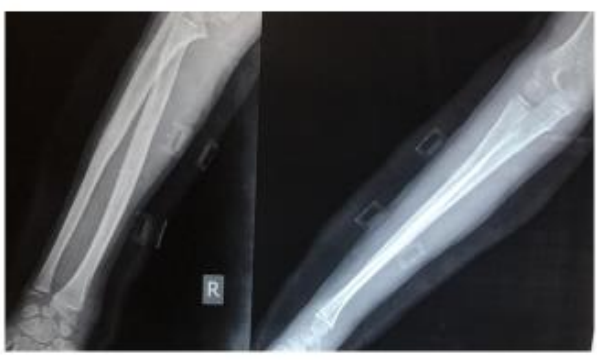

R

\section{.}


delayed union with a compound fracture, location of the fracture and necessity for open reduction. The forearm rotation arc was normal in 19 cases $(95 \%, 10$ patients in paediatric group and 9 patients in adolescent group). There was deficit in motion of about $30^{\circ}$ pronation in one patient in adolescent group (5\%). In more than $95 \%$ of cases there was less than $10^{\circ}$ of deformity at the fracture site.

There was 1 case of delayed union in adolescent group which was asymptomatic and classified as grade 1, for which no treatment was necessary. There were 3 cases of superficial infections (grade 2), out of which 1 belongs to paediatric group and remaining 2 belongs to adolescent group which was managed successfully with antibiotics. Prominent implants (grade 2) were noted in 4 cases, out of which 2 where adolescent and 2 in paediatric group. There were no neurological deficit in any patients. There were no cases of any implant migration. There were no cases of deep infections or osteomyelitis (grade 3). One case in adolescent group had delayed union which went for refracture (grade 3) and was managed conservatively in a plaster cast. There were no cases of post-operative compartment syndrome, radio-ulnar synostosis or EPL tendon rupture (grade 4) in both groups. Post-operative mortality (grade 5) was not seen in either of the age groups.

Based on Martus et al. grading system, 12 cases, 7 (70\%) patients in paediatric group and $5(50 \%)$ patients in adolescent group had excellent functional outcomes. Totally 7 (35\%) cases had good functional outcome, out of which $3(30 \%)$ belongs to paediatric and $4(40 \%)$ belongs to adolescent age group. One $(5 \%)$ case had fair outcome which was seen in adolescent group. The $\mathrm{P}$ value was 0.478 and hence there was no statistical difference between the two groups.

\section{Grade 2 complication:}
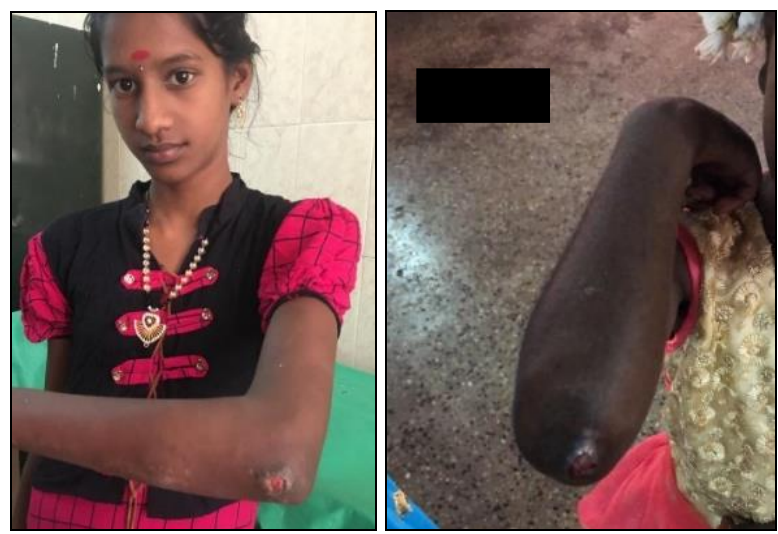

Superficial pin infection at the ulnar entry site seen in both the age groups.
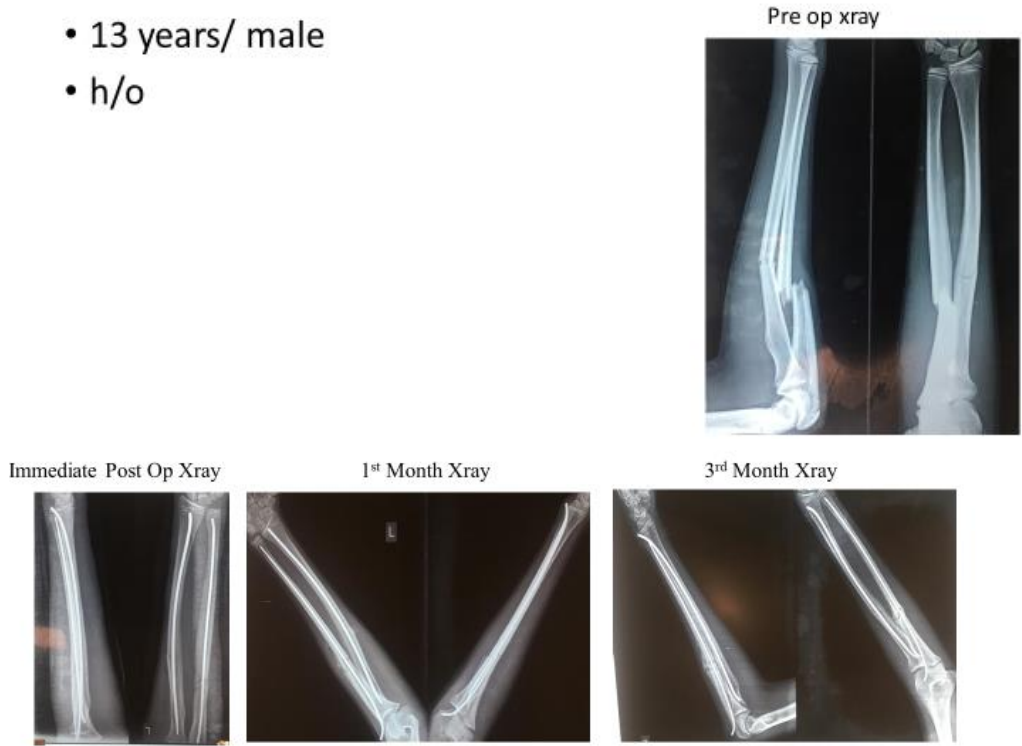

$4^{\text {th }}$ Month Xray

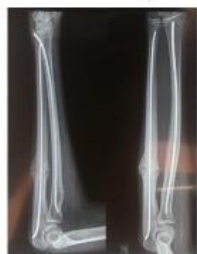

$6^{\text {th }}$ Month Xray
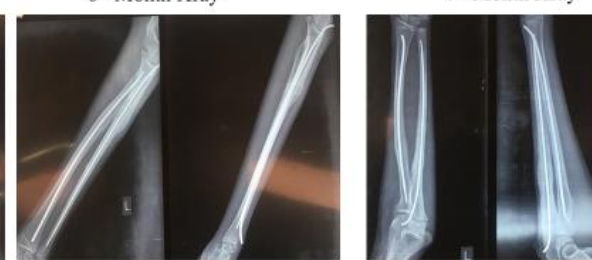

Implant Removal

Flexion

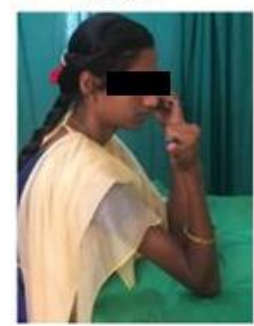

Extension
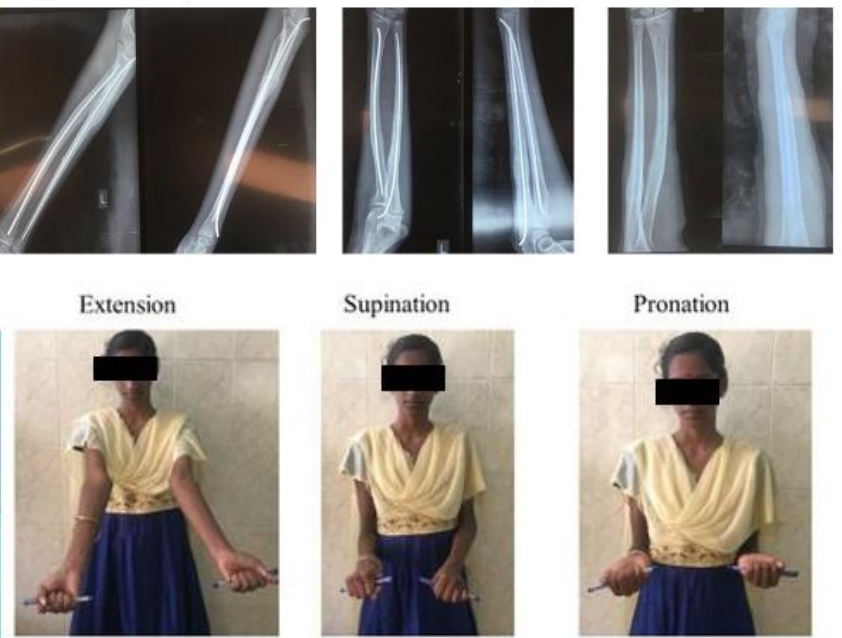

Pronation

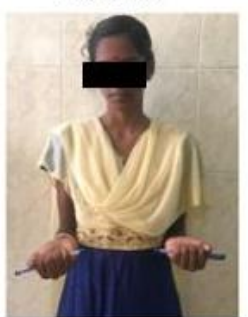

Case 3: (Adolescent group) 
Case 3: A case of asymptomatic delayed union belonging to Grade 1 complication in adolescent group, which healed with conservative management and also had full range of motion.

- 13 Years / male

- H/o RTa
Classified as excellent outcome according to Martus et al. grading system.

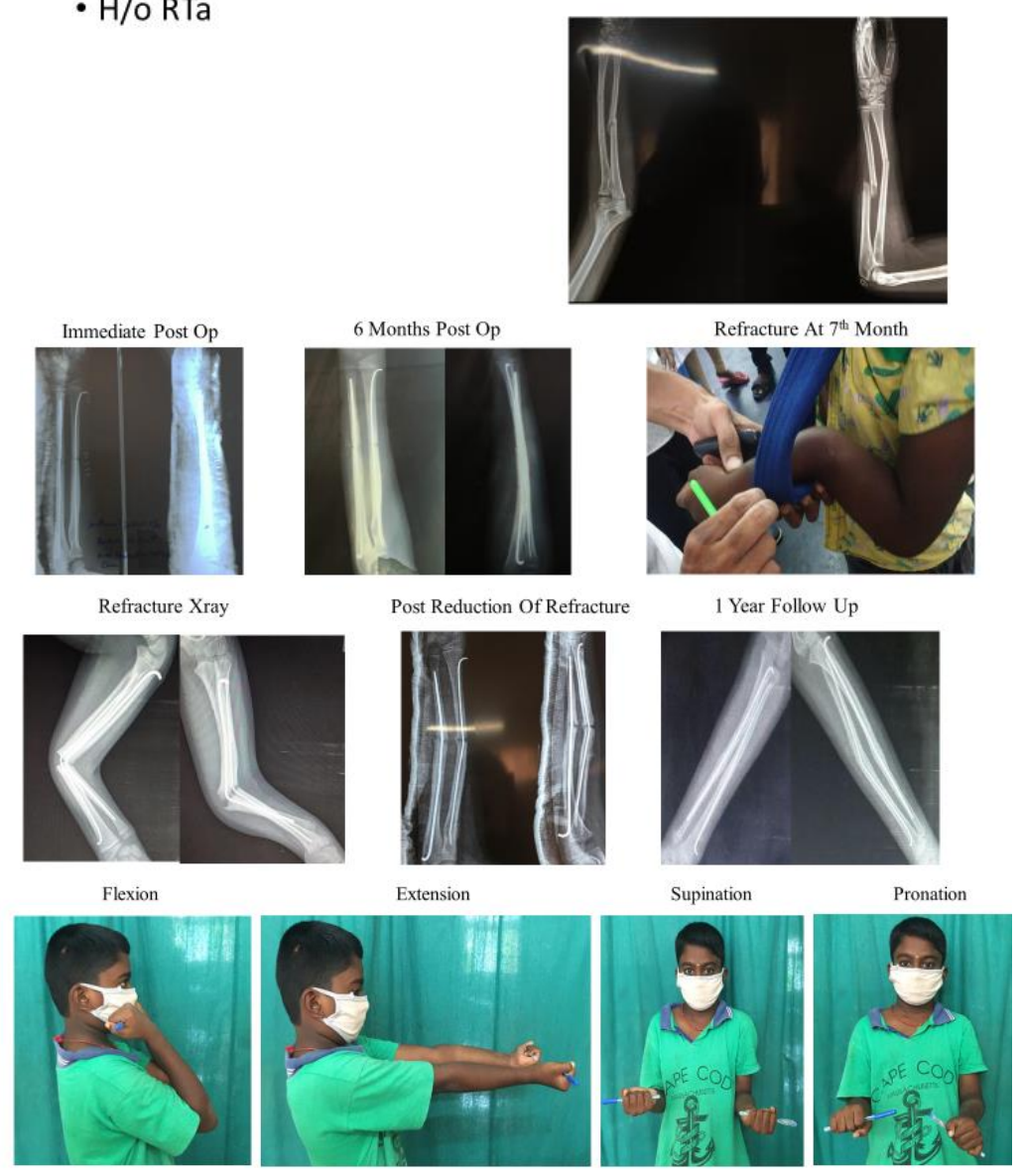

Case 4: (Adolescent group)

Case 4: A case of 13 years male child belonging to adolescent group, had delayed union presented with refracture at $7^{\text {th }}$ month belongs to grade 3 complication managed conservatively with closed reduction and plaster casting and also pronation deficit classified as fair outcome.

Table 3: Complications and outcomes

\begin{tabular}{|c|c|c|c|}
\hline & $\begin{array}{c}\text { Age }<10 \text { years } \\
\text { Paediatric group } \\
\mathbf{N}=10 \text { cases } \\
\end{array}$ & $\begin{array}{c}\text { Age }>10 \text { years } \\
\text { Adolescent group } \\
\mathbf{N}=10 \text { cases } \\
\end{array}$ & $P$ value \\
\hline \multicolumn{4}{|l|}{ Grade 1 complications: } \\
\hline Asymptomatic delayed union & 0 & 1 & \\
\hline \multicolumn{4}{|l|}{ Grade 2 complications: } \\
\hline Superficial infection & 1 & 2 & \\
\hline Prominent implant & 2 & 2 & \\
\hline Post-operative neuropraxia (transient) & 0 & 0 & \\
\hline Implant migration & 0 & 0 & \\
\hline \multicolumn{4}{|l|}{ Grade 3 complications: } \\
\hline Deep infection & 0 & 0 & \\
\hline Delayed union with refracture & 0 & 1 & \\
\hline Implant migration requiring early removal & 0 & 0 & \\
\hline Olecranon bursitis after removal requiring bursectomy & 0 & 0 & \\
\hline \multicolumn{4}{|l|}{$\begin{array}{l}\text { Grade } 4 \text { complications: } \\
\end{array}$} \\
\hline Compartment syndrome & 0 & 0 & \\
\hline Radioulnar synostosis & 0 & 0 & \\
\hline Extensor pollicis longus tendon rupture & 0 & 0 & \\
\hline \multicolumn{4}{|l|}{ Grade 5 complication: } \\
\hline Death & 0 & 0 & \\
\hline Overall complications & 3 & 6 & 0.64 \\
\hline
\end{tabular}




\begin{tabular}{|c|c|c|c|}
\hline Outcomes by Martus et al. grading system & & & \\
\hline Excellent & 7 & 5 & 0.478 \\
\hline Good & 3 & 4 & \\
\hline Fair & 0 & 1 & \\
\hline Poor & 0 & 0 & \\
\hline
\end{tabular}

\section{Discussion}

Despite a significant increase in internal fixation for the treatment of diaphyseal forearm fractures, conservative management still remains the treatment of choice ${ }^{[8]}$. In our study, the complication rate was calculated at $45 \%$ (3 complications in paediatric group and 6 complications in adolescent group). This was found to be in accordance with recent studies which showed complication rates between $14 \%$ to $45 \%[5,7,16]$. Clavien - Dindo classification was used to grade the complications, with appropriate changes (table 1). The defining feature of this classification was its uniformity in reporting complications and it was most commonly used in the field of general surgery ${ }^{[17]}$. Recently this classification has been used in orthopaedic studies with main regards to complications following surgical dislocation of hip ${ }^{[18]}$. This classification has the advantage in that it eliminates subjective bias related to grouping complications. The drawback of this classification was that, it has been widely accepted in general surgical studies ${ }^{[9,10]}$, however its validation in orthopaedic paediatrics has not been well accepted. Regardless, this classification has been used in the postoperative complications of paediatric surgery ${ }^{[19,20]}$.

The most commonly used classification for diaphyseal forearm fractures was given by price et al. ${ }^{[13]}$, which was similar to Daruwalla, Grace and Eversmann. A patient was said to have excellent functional outcome when there was no complaints and deficit in motion was less than $10^{\circ}$. Good result was documented, when the patient had mild discomfort with strenuous activity and the deficit in motion was in the range of $11^{\circ}$ to $30^{\circ}$. Fair result was reported, when the patient had difficulties with day to day activities and the deficit in motion was between $30^{\circ}$ to $90^{\circ}$. Poor result was suggested when there were more complaints and severe restriction in movements. Limitation of price et al. grading was that, it was basically designed for classifying results of conservative management and that it failed to take into account the postoperative complications in the final outcome. Additionally, a drawback of price grading was that deficit in forearm motion in the range of $30^{\circ}$ to $90^{\circ}$ was considered to be a fair outcome, however this fair grade was in reality a poor outcome with considerable disability in function with regards to ADL.

Another recent addition to these classifications was the children's hospital of Philadelphia forearm outcome score described by Flynn et al. ${ }^{[5]}$ According to this classification, a patient was said to have excellent functional outcome if ROM was full, which means the loss of supination and pronation was less than $10^{\circ}$ with no complaints. A patient was said to have a fair outcome when the deficit in range of motion was less than $30^{\circ}$ with or without a complication which was minor and resolving. Poor result was said when the deficit in motion was more than $30^{\circ}$ with a major complication. Our study was in accordance with Flynn et al. in that, the deficit in motion greater than $30^{\circ}$ was considered to be a poor outcome. Another classification called CHOP classification classified complications into major and minor categories but however we were concerned regarding their influence in the final outcome. Martus et al. suggested that a classification that has to be used, should not affect the final result, it should be transient and should avoid preclusion of a good final outcome.
An ideal example would be a superficial infection, resolving with oral antibiotic therapy, would not affect the final outcome and should not be classified as a fair outcome. Additionally, a delayed union which is asymptomatic and eventually unites without any surgical intervention should not be classified as a poor outcome. The basis of this system was taken from prior classifications and took into account the minimal pronation and supination needed for ADL. Raiss et al. ${ }^{[1]}$ and Sardelli et al. ${ }^{[2]}$ in their studies of ADL using 3D analysis came to the conclusion that, the minimum forearm rotation that was required was between $55^{\circ}$ pronation to $72^{\circ}$ supination. A basic definition suggested that, the normal forearm range of motion would be between $70^{\circ}$ pronation to $85^{\circ}$ supination ${ }^{[14,15]}$, and according to these studies a deficit of $5^{\circ}$ to $30^{\circ}$ pronation and a deficit of $8^{\circ}$ to $35^{\circ}$ supination significantly interfered with ADL and the outcome of our study was based on these data. The advantages of Martus et al. ${ }^{[11]}$ grading system when compared with previous ones were (1) a strong emphasis that a deficit of greater than $30^{\circ}$ means a poor outcome, (2) an objective means for stratifying complications, (3) classifying an outcome as good, if the deficit in motion was less than $10^{\circ}$ with self-limiting postoperative complications or complications that subside on an outpatient basis. Grade 2 complications were seen in four patients of which 3 ( 1 in paediatric and 2 in adolescent) of them had superficial infection. There were no cases of postoperative neuropraxia or any neurological deficit.

Delayed union following TENS nailing of paediatric forearm was well documented previously and was mostly seen in the ulna, in ages above ten years, surgeries involving open reduction of the fracture site or a compound fracture $[5,7,12,21$, ${ }^{22]}$. Similarly, our study found correlation of delayed union with age greater than 10 years, but not with compound fracture or fractures involving open reduction.

In our study a refracture occurred in one patient with implant in-situ and it was related to a delayed union which was classified under grade 3 complication. We treated the fracture conservatively by plaster casting with the implant in-situ until the fracture united.

Radio-ulnar synostosis is a very infrequent complication of diaphyseal paediatric forearm fractures, usually seen in cases with high velocity trauma. However, we did not encounter any such complication. EPL rupture is a known complication following dorsal entry of the TENS nail in the radius ${ }^{[23,24,25]}$. In our study, in 6 cases ( 2 adolescent and 4 paediatric), the point of entry in the radius was in the dorsal aspect, however we did not encounter any case of post-operative EPL rupture. Closely associated with this entry site, is the superficial radial nerve and it is frequently affected in dorsal entry nails, nevertheless we noted no such case of post-operative neuropraxia. There were no cases of compartment syndrome neither preoperatively nor post operatively. This could be attributed to shorter operative duration which was in accordance with Yuan et al ${ }^{[8]}$, who suggested early conversion of closed to open reduction when the former failed.

To conclude, our study showed that the incidence in complications were slightly higher in the adolescent age group. However statistically $(\mathrm{P}=0.478)$ there were no 
significance between these groups. The limitation of this study was a smaller sample size, less duration of the study. A larger sample size with an extensive follow-up could yield different results. Based on our results, the usage of TENS as intramedullary nail fixation in adolescent age group yields good results even with minimal complications. Preoperative counselling regarding the possible complications should be explained to the patient before surgery.

\section{References}

1. Raiss P, Rettig O, Wolf S et al. Range of motion of shoulder and elbow in activities of daily life in 3D motion analysis. Z Orthop Unfall 2007;145:493-498.

2. Sardelli M, Tashjian RZ, MacWilliams BA. Functional elbow range of motion for contemporary tasks. J Bone Joint Surg Am 2011;93:471-477.

3. Noonan KJ, Price CT. Forearm and distal radius fractures in children. J Am Acad Orthop Surg 1998;6:146-56.

4. Amit Y, Salai M, Chechik A. Closed intramedullary nailing for the treatment of diaphyseal forearm fractures in adolescence: a preliminary report. J Pediatr Orthop 1985;5:143-146.

5. Flynn J, Jones KJ, Garner MR et al. Eleven years experience in the operative management of pediatric forearm fractures. J Pediatr Orthop 2010;30:313-318.

6. Lascombes P, Prevot J, Ligier JN. Elastic stable intramedullary nailing in forearm shaft fractures in children: 85 cases. J Pediatr Orthop 1990;10:167-171.

7. Kang SN, Mangwani J, Ramachandran $\mathrm{M}$ et al. Elastic intramedullary nailing of paediatric fractures of the forearm: a decade of experience in a teaching hospital in the United Kingdom. J Bone Joint Surg Br 2011;93:262265.

8. Yuan P, Pring ME, Gaynor TP et al. Compartment synrome following intramedullary fixation of pediatric forearm fractures. J Pediatr Orthop 2004;24:370-374.

9. Clavien P, Barkun J, de Oliveira ML et al. The ClavienDindo Classification of surgical complications. Ann Surg 2009;250:187-196.

10. Dindo D, Demartines N, Clavien P. Classification of surgical complications: a new proposal with evaluation in a cohort of 6336 patients and results of a survey. Ann Surg 2004;2004:205-213.

11. Martus JE, Preston RK, Schoenecker JG, Lovejoy SA, Green NE, Mencio GA. Complications and outcomes of diaphyseal forearm fracture intramedullary nailing: a comparison of pediatric and adolescent age groups. J Pediatr Orthop 2013;33(6):598-607.

12. Schmittenbecher P, Fitze G, Go“ deke J et al. Delayed healing of forearm shaft fractures in children after intramedullary nailing. J Pediatr Orthop 2008;28:303306.

13. Price C, Scott DS, Kurzner ME et al. Malunited forearm fractures in children. J Pediatr Orthop 1990;10:705-712.

14. Wagner C. Determination of rotatory flexibility of the elbow joint. Eur J Appl Physiol Occup Physiol 1977;37:47-59.

15. Youm Y, Dryer RF, Thambyrajah K et al. Biomechanical analyses of forearm pronation-supination and elbow flexion-extension. J Biomech 1979;12:245-255.

16. Smith VA, Goodman HJ, Strongwater A et al. Treatment of pediatric both-bone forearm fractures: a comparison of operative techniques. J Pediatr Orthop 2005;25:309-313.

17. Clavien P, Strasberg S. Severity grading of surgical complications. Ann Surg 2009;250:197-198.
18. Sink EL, Beaule' PE, Sucato D et al. Multicenter study of complications following surgical dislocation of the hip. $\mathbf{J}$ Bone Joint Surg Am 2011;93:1132-1136.

19. Soon IS, Wrobel I, deBruyn JC et al. Postoperative complications following colectomy for ulcerative colitis in children. J Pediatr Gastroenterol Nutr 2012;54:763768.

20. Harraz AM, Shokeir AA, Soliman SA et al. Toward a standardized system for reporting surgical outcome of pediatric and adolescent live donor renal allotransplantation. J Urol 2012;187:1041-1046.

21. Lobo-Escolar A, Roche A, Bregante J et al. Delayed union in pediatric forearm fractures. $\mathrm{J}$ Pediatr Orthop 2012;32:54-57.

22. Fernandez FF, Eberhardt O, Langendo" rfer M et al. Nonunion of forearm shaft fractures in children after intramedullary nailing. J Pediatr Orthop B 2009;18:289295.

23. Pugh DM, Galpin RD, Carey TP. Intramedullary steinmann pin fixation of forearm fractures in children. Long-term results. Clin Orthop Relat Res 2000;376:3948.

24. Kravel T, Sher-Lurie N, Ganel A. Extensor pollicis longus rupture after fixation of radius and ulna fracture with titanium elastic nail (TEN) in a Child: a case report. J Trauma 2007;63:1169-1170.

25. Cumming D, Mfula N, Jones JW. Paediatric forearm fractures: the increasing use of elastic stable intramedullary nails. Int Orthop 2008;32:421-423.

26. Blakemore L, Cooperman DR, Thompson GH et al. Compartment syndrome in ipsilateral humerus and forearm fractures in children. Clin Orthop Relat Res 2000;376:32-38. 